\title{
Ethics consultation on demand: concepts, practical experiences and a case study
}

Stella Reiter-Theil Albert Ludwigs University, Freiburg, Germany

\begin{abstract}
Despite the increasing interest in clinical ethics, ethics consultation as a professional service is still rare in Europe. In this paper I refer to examples in the United States. In Germany, university hospitals and medical faculties are still hesitant about establishing yet another "committee". One of the reasons for this hesitation lies in the ignorance that exists here about how to provide medical ethics services; another reason is that medical ethics itself is not yet institutionalised at many German universities. The most important obstacle, however, may be that medical ethics has not yet demonstrated its relevance to the needs of those caring for patients.

The Centre for Ethics and Law, Freiburg, has therefore taken a different approach from that offered elsewhere: clinical ethics consultation is offered on demand, the consultation being available to clinician(s) in different forms.

This paper describes our experiences with this approach; practical issues are illustrated by a case study.

(Fournal of Medical Ethics 2000;26:198-203)
\end{abstract}

Keywords: Ethics consultation; hospital ethics committee; critical decisions; medical ethics in Germany

\section{Introduction}

An ethics consultation, offered as a professional service of clinical medical ethics within a university hospital, has only recently become available in Germany. It has, however, been practised for some ten to 15 years in the United States, following various protocols. ${ }^{1-4}$ In Great Britain and also in Italy there have been attempts to establish hospital ethics committees. ${ }^{5-7}$ However, in Britain, as in much of Europe "clinical ethics committees are rare and have so far not found much favour amongst clinicians". ${ }^{8}$ One of the major differences between the services offered in different countries and institutions concerns the question of whether the consultation is done routinely by a permanent body (such as a hospital ethics committee [HEC]) or only on demand and according to the needs of the clinicians involved. Within the hospital setting an ethics committee could prove itself to be a competent-or could even be an obligatory- agent in critical decision making and it could also play a decisive role in formulating ethical guidelines for the hospital concerned. Alternatively, clinical ethics consultation could be offered as a service on a more individual and flexible basis, without setting up a full and permanent committee. In this paper I describe our experience at the University Hospital of Freiburg of providing this latter type of "on demand" clinical ethics support.

In Germany, clinical medical ethics as such is not yet an integral part of university hospitals and medical faculties. ${ }^{9}$ However, German hospitals belonging to the catholic and protestant churches have proposed that competent boards or hospital ethics committees should be established at all hospitals in order to offer ethics consultation in difficult cases of critical decision making. University hospitals, which are independent of church affiliation, have no such policy. In fact, Freiburg is unique in Germany in being a university hospital with a clinical ethics consultation service. Being the only institution of its kind, ie one that is built within the structure of a university hospital, the Centre for Ethics and Law in Medicine (ZERM), Freiburg, founded in 1996, is particularly well placed to collaborate with clinical units on an everyday basis and to provide ethics support services according to individual needs.

Because ethics consultation is likely to be a developing area, an initiative has been started by the author together with her colleague, F J Illhardt, to set up a network of professionals active in ethics consultation or interested in becoming qualified to practise ethics consultation. In October, 1998, the Akademie der Wissenschaften und der Literatur, Mainz hosted the first meeting of a German network in the field of ethics consultation; the second meeting was held in January 2000. Different concepts, methods and settings were presented and discussed. The clinicians involved stated in the evaluation following the two meetings that the need for ethics consultation was obvious, particularly in the care of the critically ill or in the care of patients where different parties' interests clash. It was recognised that there was a 
need to formulate quality control criteria for the outcome of decisions, and also for the competence of the providers of such services. Another concern was the availability of ethics consultation for patients themselves and for their relatives. These issues need further elaboration and will be discussed at a future meeting.

\section{Why is ethics consultation necessary? Why is it important?}

There is evidence among clinicians of difficulties in everyday clinical practice which require ethical competence, particularly in the treatment of severely ill patients. There also seems to be a growing interest in, and open-mindedness towards, seeking help in making the ethical dimensions of critical decisions clear, by consulting professional medical ethicists. What are the reasons for this recent development?

One of the reasons for the increasing ethical awareness in the health sector is the plurality of values. Not only different religious values or contrasting political ideologies, but also a plethora of lifestyles and personal preferences, make it almost impossible to generalise from one individual's wishes to other patients about, for instance, how to handle the doctrine of truth-telling at the bedside, or how to live the last weeks and days at the end of life.

Another reason for the need for ethical competence and advice stems from the expansion of medical interventions as such. It is the nature of the internal dynamics of medicine that practice is continuously changing through the limitless progress of research and its application. Among the many examples of the challenges created by expansion and innovation are the possibilities of prolonging the life of critically ill patients, even beyond limits which seem reasonable from a medical or commonsense perspective. ${ }^{10}$

As a result, dying in hospital has become a major ethical issue which is widely debated both by the public and the medical profession. ${ }^{11-13}$ Ethical dilemmas include defining the meaning of "basic care" and clarifying whether this should include artificial feeding, hydration and ventilation, or whether these forms of life-sustainment should be defined as "therapy", with the possible consequence that they might be withdrawn from the patient. Ethical dilemmas may arise from the patient's wishes as such, from the question of whether to follow these wishes or not, or from the difficulty of discovering what the patient's wishes actually are.

Closely linked to the complex issues of terminal care is the growing involvement or influence of legal aspects in clinical decision making. Some- times ethical awareness seems to be motivated by a certain defensiveness on the part of doctors who are trying to avoid legal risk. This question is - among others - a matter of rational and legitimate interest for any ethical investigation. Only if self interest and self defensiveness are a doctor's sole motivation will it be difficult to stimulate ethical discourse. In such a case it is the task of the consultant to find a balance between the professional's interests and those of the patient.

Economic constraints are having an increasing impact on clinical decision making in Germany as elsewhere, if not at the level of individual treatment (micro allocation), certainly at the level of national health policy and hospital policy. The economic dimension of medical practice puts pressure on individual health professionals as well as on administrators. In this domain, and also in many other respects, the experience of ethical conflict has become common to all parties involved: doctors, nurses, patients, and family. The experience of ethical conflict, however, should not be considered a negative issue. To become aware of ethical conflict and to be capable of formulating explicitly the clash of ethical principles and values, is a crucial factor in reflective and responsible patient care. ${ }^{14}$

At the university hospital in Freiburg ethics consultation is practised solely at the request of clinicians in need of help, and not on the initiative of the ethics professionals themselves. The requesting clinician also has the opportunity of influencing the setting for ethics consultation, in that he can choose between an individual and a group session.

Two working groups located in Munich and Freiburg (directed by Hiddemann and ReiterTheil) are carrying out a special research project. This involves documenting and analysing the conditions of treatment at the end of life in oncology, neonatology, perinatology and intensive care. In addition, the needs for assistance in the clarification of ethical problems, in the ethical reasoning about the pros and cons of different treatment options and in the decision making process are being assessed as part of this research project in order to help develop, on the basis of empirical evidence, the most effective ethics support service.

As a preliminary categorisation of the problems dealt with in ethics consultation we can distinguish four major types: conflict between ethical principles, for example about treatment and care at the end of life, mostly experienced by the doctor; uncertainty, for example about the patient's wishes or best interests; dissent between the parties involved, and difficulties, for example with 
"non-compliant" patients who may be at risk of hurting themselves.

There is often more than one category involved as is made clear in the case example discussed below in section 4 . All four categories mentioned represent the perspectives of the health professionals seeking advice, not the view of the patient directly. This is due to our limited experience of ethics consultation, which is restricted to helping colleagues. Patients in Freiburg have so far rarely made use of direct access to ethics consultation. Although this has been discussed recently, we have little practical knowledge or documentation about patients' needs in this respect. It seems probable that patients' needs would have very different foci, since those seeking ethics consultation would obviously not be either patients at the point of death or comatose patients. Yet the treatment of both these kinds of patient often causes ethica problems for doctors and nurses. Furthermore it may well be that patients would wish to express criticism about care or communication in the hospital rather than ethical problems to do with difficult clinical decision making. Another group of potential "clients" of ethics consultations are the relatives of critically ill patients, from whom, as stipulated by German legislation, surrogate consent can be sought. Once again, there have been few cases in which the relatives directly asked for ethics consultation. Yet it does happen routinely that relatives as well as legal representatives of patients are invited to participate in ethics consultations and to give their opinion. One example will be given in the following case report below (see section 4). In a special "pre-clinical" domain, ZERM offers help with the formulation of living wills $^{13}$ to (potential) patients and their relatives who are seeking information and advice from medical ethics professionals.

\section{The four principles}

Another important issue concerns the ethical principles which are used to present an ethical structure and orientation to those in need of help. It is evident that the well-known attempt to offer a framework suitable for pluralistic societies, namely the four principles approach of Beauchamp and Childress, ${ }^{15}$ fits well with the needs of a flexible ethics consultation. The principles 1 . respect for autonomy, 2. non-maleficence, 3 . beneficence, and 4 . justice can be introduced easily. Important and sometimes prominent are both the principles "respect for autonomy" and "justice", which are the focus of much debate. But although this approach has intentionally been kept "neutral" in some areas of ethical debate, such as the right to life, it is necessary to add at least two additional basic ethical concepts for thorough ethical scrutiny: life protection and its limits, and control of third parties' interests.

\section{How does ethics consultation on demand work?}

The ethics consultation service in Freiburg works in different settings:

a) An individual doctor/nurse seeks ethics consultation (EC) from a member of the Centre for Ethics and Law in Medicine (ZERM);

b) A clinical team asks for EC from a member of ZERM;

c) The director of a clinical department asks for EC from a group of ZERM members, and

d) Grand rounds in the hospital discuss cases for EC with a group of ZERM members and guests (the so called Ethik-Tag).

From this variety of settings it becomes obvious that the procedures and methodologies of ethics consultation have to be applied somewhat flexibly in a problem-oriented and person-oriented form. On the other hand, the variety of settings does require the consultant to use a systematic framework to structure and lead the process of exchanging views, moral reasoning and evaluating options. The ethical principles discussed accord well with the operating logic underlying ethics consultaton, as does an approach incorporating a systematic change of perspectives in order to ensure fair consideration of the views of all the parties involved. The systematic change and exchange of perspectives has to cover:

a) The reflection of the interests of the individuals involved (the patient, relatives, the doctors, nurses, therapists);

b) The analysis of the relationship between the patient (relatives) and the professionals;

c) The relevant social context such as family, friends, workplace on the part of the patient, while on the part of the professionals, the team, colleagues, hierarchy and related issues must be considered;

d) The societal and legal circumstances of the treatment as well as the cultural and political context;

e) Acknowledgement of the universal ethical principles which serve as general ethical orientation. ${ }^{16}{ }^{17}$

Besides this ethical methodology, a set of rules should be available for ethics consultation. ${ }^{18}$ It is an ideal requirement that the moderation should be done by the ethics consultant, not by the person presenting the problem or case, nor by the leader of the clinical unit involved. In fact, we have 
been practising many forms and combinations in order to find out what functions best in a specific context. There is at least one strong argument for professional moderation from the ethics side: as far as those with different professional experience and hierarchical positions are involved, an independent moderator is more likely to guarantee a full exchange of all perspectives than a professional who is a member of the clinical team. Therefore, we suggest that the ethicist be the moderator and that he or she must have adequate training in counselling and communication. This raises the question of which professional and academic qualifications are necessary for a good ethics consultant.

It is evident that no expertise is possible in this domain without a deep knowledge and analytical capacity in ethics itself. This can be developed during regular philosophical or theological studies.

Special academic qualification in medical ethics is another objective criterion (graduate, postgraduate or postdoctoral degree).

Also of great importance is competence in one of the health professions such as medicine, nursing or clinical psychology and a considerable experience in patient care. It may well be, however that a hospital chaplain is clinically more knowledgeable and experienced than someone qualified in medicine who turned to theoretical research very early. Therefore, these criteria should be applied "ad personam", considering the person's individual background and potential. It may also be possible that a clinical ethics curriculum prepares candidates adequately for practice.

Without professional communicative competence all the intellectual and technical skills are useless, because ethics consultation is a complex interactive experience.

Last but not least, the personality of the ethics consultant must be developed and trained in specific ways. Preliminary suggestions for the personal qualification of an ethics consultant are: he or she should have the ability a) to bear and to understand severe and sometimes unsolvable conflict, b) to feel and to show empathy, c) to keep a professional distance, d) to guarantee a nonjudgmental attitude towards the parties involved, e) to represent those who cannot adequately represent and defend their views themselves, $\mathrm{f}$ ) to resist reductionism of ethical issues to medical, psychological or other "technical" terms and to make the ethical implications of options explicit at any time.

Ethics consultation will mostly deal with cases where the chances of therapeutic success are very limited. Also, ethics consultants often have to share the same time constraints to which the clinicians themselves are subjected. The need for improvisation resulting from time pressure should help all participants to focus and to evaluate the results of the process in a realistic way. Ethics consultation should take place in an atmosphere allowing for constructive and open reflection on the basis of mutual respect and trust.

\section{A case study of ethics consultation: does the operation make sense?}

The following example of an ethics consultation was initiated by a clinical team asking for ethics consultation from an individual member of ZERM (the author). The patient was a 50year-old unmarried man, who had a social worker as legal guardian because of his multiple handicaps. His family consisted of two sisters, both working, who lived in the area and cared for their brother as far as they were able. Since 1984 the patient's history included large hypertensive cerebral haemorrhages in the region of the basal ganglia and convulsive seizures in connection with alcohol abuse. In February 1997 a carcinoma of the right kidney was diagnosed with an indication for operation, but the patient refused to give his consent. In November 1997 once again large cerebral haemorrhages occurred in the region of the basal ganglia with multiple neurogenic disorders resulting (haemiplegia, concentration deficit and others) and tracheotomy became necessary.

In June 1998 the patient was admitted to the university hospital, a diagnosis of the kidney carcinoma was made and the question of whether an operation was indicated was deliberated. The patient wrote down his consent to operation with the precondition, "if it makes sense". The benefit of surgery was unclear: on the one hand there was no evidence of metastases so that surgery offered a chance of prolonging life for a few years, on the other hand there was a high risk of further neurological damage under anaesthesia.

The senior resident put the patient's question forward for discussion: does the operation make sense? The ethicist was called in to help find the answer. The senior resident distinguished two relevant issues: is it ethically right to perform the operation given the uncertain prognosis; and, is it right given limited resources?

During the consultation, further questions arose: how shall the patient's wishes be handled; how can he be adequately involved; what is in the best interests of the patient, and how can additional strain on the patient be best avoided?

At the first meeting the clinical team, the patient's legal guardian, and the medical ethicist (author) were present. The medical history was 
summarised by a young intern assisted by the senior resident and two nurses; the root of the problem was formulated by the senior resident. After a preliminary clarification of the situation and of the task of the ethics consultation, the medical ethicist was asked to give her opinion. She considered the information provided insufficient to lead to a decision about whether the operation would "make sense" or not, particularly with respect to the anaesthetic risk. The participants agreed to consult an anaesthetist before continuing with the ethical discussion.

At the start of the meeting it had been very important to clarify that the ethics consultation would not serve as an instrument of rationing or decision making in respect of resource allocation in the individual case. The patient's right to the best treatment available was not to be questioned: no recommendation to forgo treatment for financial reasons would be made. Much time was spent on the question of whether the patient had recently shown any signs of refusing treatment, as had previously been the case. The legal guardian pleaded that the patient had a will to live and for him to have an operation "if it makes sense". An operation would be accompanied by many burdens for the patient. Discussion followed as to who should communicate with the patient about the issues at hand and how this could be done.

\section{Too confused}

The group asked the medical ethicist (who is also a trained clinical psychologist) to see the patient and evaluate the possibilities of informing and involving the patient in an adequate way. The following day the patient's condition deteriorated so that he was transferred to the intensive care unit. The medical ethicist saw him there and followed a nurse's attempts to communicate with him about simple subjects. As these attempts failed, the ethicist decided that the patient was too weak and too confused for communication about difficult issues such as the possible risks and benefits of an operation, at least at that time.

The second meeting had different participants. The members of the clinical team had changed except for the senior resident; the legal guardian of the patient had been replaced by a colleague because of holidays. Both sisters of the patient were present as a result of a specific invitation. The ethicist was the same.

Initially, the "homework" after the first meeting was presented and discussed. The senior resident summarised the information he had received about the anaesthetic risk, which was considerable, but difficult to estimate. The ethicist reported on the visit at the patient's bedside in the intensive care unit and recommended no further discussion with the patient about the operation, but adherence to the wishes he had already expressed. This recommendation was made because of the patient's condition: he was able to listen, but could not express his views by speaking or writing; he could only make eye contact and it was obvious that every attempt to interpret his facial expression (wrongly?) stimulated severe distress in the patient who was not able to comment.

As the legal guardian again argued in favour of an operation to give the patient a chance to live longer, discussion was centred on what was in the best interests of the patient. Additional information about the patient's wishes during the last few years came from his sisters. They reported that since his illnesses, he had done best in a particular rehabilitation institution. They described the small improvements he had made there after transfer from the hospital; for example, he had regained some interest in people and in activities such as watching TV while sitting in a wheelchair.

In the light of the patient's poor neurological and psychological situation, the consensus was found that an operation and particularly the related burdens (another long stay in the hospital) would destroy, probably for a long time, his remaining chances of some quality of life. Without an operation he would soon have the chance to return to the rehabilitation institution, where he had already improved a couple of times and where he had achieved some form of self determination and enjoyable activity. Emphasis was put on the careful preparation of transferral and continuing support.

\section{Further development}

The goals of ethics consultation correspond with the ethos of practical medicine and health care. This means that ethics consultation is by no means "neutral" or "value free", but, like any treatment or intervention, it has to prove its value on the basis of the universal ethical principles demanded of medicine itself. Ethics consultation transcends medical practice insofar as it undertakes a systematic approach in order to make underlying ethical values, conflicts or options explicit, and to open them to discussion and evaluation-before or after decision making.

During the coming years more experience and reflection will be needed regarding methodology as well as documentation. Another challenge will be to standardise procedures and the evaluation of outcomes in order to pave the way for quality assessment. These achievements will only be possible if local groups active in ethics consultation share their experiences and difficulties and work 
together to make this service a reliable source of advice and assistance when difficult ethical decisions have to made.

\section{Acknowledgements}

This paper is dedicated to the 65th birthday of Professor Dr Dr h c Hanjörg Just, Freiburg.

I am grateful for the generous assistance of the Akademie der Wissenschaften und der Literatur, Mainz, and in particular to Emeritus Professor Dr Dr h c Paul Schölmerich, for help with the setting up a German network for ethics consultation. Also I am grateful for grants from the German Research Council (Bonn) and the Robert Bosch Foundation (Stuttgart) for clinical ethics research projects (directed by Professor Dr Wolfgang Hiddemann, Munich, and Privatdozentin Dr Stella Reiter-Theil, Freiburg). I would also like to acknowledge helpful comments on the first version of my paper from Tony Hope and Eckhard Herych as well as from anonymous reviewers of the Fournal of Medical Ethics.

Stella Reiter-Theil is a Medical Ethicist and the Research Co-ordinator of ZERM, and Senior Lecturer in Medical Ethics in the Medical Faculty of Albert Ludwigs University, Freiburg, Germany. Address for correspondence: Privatdozentin Dr Stella ReiterTheil, Dipl-Psych, Center for Ethics and Law in Medicine, University Hospital, Albert-LudwigsUniversität, Freiburg, Elsässer Str 2m, 1a, D-79110 Freiburg, Germany.

\section{References}

1 Ackerman TF, Graber GC, Reynolds $\mathrm{CH}$ and Thomasma DC, eds. Clinical medical ethics. Exploration and assessment. Lanham, New York, London: University Press of America, 1987.

2 LaPuma J, Schiedermayer D. Ethics consultation. A practical guide. Boston, London: Jones and Bartlett, 1994.
3 Fletcher JC, Quist N, Jonsens AR, eds. Ethics consultation in health care. Ann Arbor: Health Administration Press, 1989.

4 Zaner RM. Ethics and the clinical encounter. Englewood Cliffs, NJ: Prentice Hall, 1988.

5 Larcher VF, Lask B, McCarthy JM. Paediatrics at the cutting edge: do we need clinical ethics committees? Fournal of Medical Ethics 1997;23:245-9.

6 Cattorini P, Mordacci R. Ethics committees in Italy. HEC Forum 1992;4,3:219-26.

7 Meslin EM, Rayner C, Larcher V, Hope T, Savulescu J. Hospital Ethics Committees in the United Kingdom. HEC Forum. 1996;8,5:301-15.

8 Gillon R. Clinical ethics committees - pros and cons. Fournal of Medical Ethics 1997;23:203-4

9 Reiter-Theil S. Answers to change: the problem of paradigm shift in medical ethics from the German perspective. In: Tröhler U, Reiter-Theil S, eds. Ethics codes in medicine. Foundation and achievements of codification since 1947. Aldershot, Brookfield USA, Singapore, Sydney: Ashgate, 1998: 257-69.

10 Schuster HP. Ethische Probleme im Bereich der Intensivmedizin. [Ethical problems in the field of intensive care medicine.] Internist 1999:40,3:260-9.

11 Klaschik E. Sterbehilfe - Sterbebegleitung. [Aid in dying - palliative care.] Internist 1999;40,3:276-82.

12 Reiter-Theil S. Therapiebegrenzung und Sterben im Gespräch zwischen Arzt und Patient - Ein integratives Modell für ein vernachlässigtes Problem. [Evaluating the limits of therapy in doctor-patient-conversation. An integrative model for a neglected issue.] Ethik in der Medizin 1998;10:74-90.

13 Reiter-Theil S. Ethische Aspekte der Patienten-Verfügung. Eine Chance zur Gestaltung des Sterbens. [Ethical aspects of living wills. A chance for end-of-life-care planning.] Forum DKG 1998;13:262-8

14 Reiter-Theil S, Hiddemann W. Ethik in der Medizin: Bedarf und Formen. [Ethics in medicine. Needs and forms.] Internist 1999;40,3:246-54.

15 Beauchamp TL, Childress JF. Principles of medical ethics[4th ed]. Oxford, New York: Oxford University Press, 1994

16 Reiter-Theil S. Ethische Probleme in der Klinischen Psychologie. [Ethical problems in clinical psychology.] In: Ehlers A, Hahlweg K, eds. Enzyklopädie der Psychologie, 1. Hogrefe, Göttingen, Bern, Toronto, Seattle: Grundlagen der Klinischen Psychologie, 1996.

17 Reiter-Theil S. Ethik in der Klinik - Theorie für die Praxis: Ziele, Aufgaben and Möglichkeiten des Ethik-Konsils. [Ethics in the hospital - theory for practice: goals, tasks and chances of ethics consultation.] Ethik in der Medizin 1999; 11,4:222-32.

18 Höger C, Reiter-Theil S, Reiter L, Derichs G, Kastner-Voigt M, Schulz T. Fallbezogene ethische Reflexion. Ein Prozeßmodell zur Ethik-Konsultation in der Kinderpsychiatrie und Psychotherapie. [Case-related ethical reflection. A procedural model of ethics consultation in child psychiatry and psychotherapy.] System Familie 1997;10:174-9. 